\title{
Preparation of an Electrochemical Sensor Based on a Nitrogen- Doped Graphene Modified Electrode and its Application for the Detection of Methyl Parathion
}

\author{
Xiao-Ya Dong*, Feng Wang, Jing Ma, Bai-Jing Qiu* \\ The Key Laboratory of Modern Agricultural equipment and technology (MOE), The Key Laboratory of \\ Plant Protection Engineering, High-tech Key Laboratory of Agricultural Equipment and Intelligence of \\ Jiangsu Province, School of Agricultural Eqipmental Engineering, Jiangsu University, Zhenjiang \\ 212013, Jiangsu, PR China \\ "E-mail: dongxiaoya@ujs.edu.cn (Xiao-Ya Dong); qbj@ujs.edu.cn (Bai-Jing Qiu)
}

doi: $10.20964 / 2019.12 .02$

Received: 23 April 2019 / Accepted: 28 August 2019 / Published: 29 October 2019

We report a simple and sensitive electrochemical sensor that was successfully fabricated by using a nitrogen-doped graphene (NG)-modified glassy carbon electrode (GCE) for the electrocatalytic oxidation of methyl parathion (MP). The electrochemical behaviours of MP with the modified electrodes were investigated using cyclic voltammetry $(\mathrm{CV})$ and differential pulse voltammetry (DPV). Due to its unique structure and properties, which originated from the nitrogen doping, NG showed high electrocatalytic activity towards MP in phosphate-buffered saline (PBS). The electrochemical sensor had a broad dynamic linear range and detection limit of $0.017 \mu \mathrm{M}$. Under optimized conditions, the proposed sensor showed good stability and satisfactory selectivity. When applied for the detection of MP in river samples, the NG/GCE sensor demonstrated good recovery rates. This work might find promising applications in developing a new type of enzyme-free sensor.

Keywords: Nitrogen-doped graphene, Electrochemical sensor, Methyl parathion, Modified electrode

\section{$\underline{\text { FULL TEXT }}$}

(C) 2019 The Authors. Published by ESG (www.electrochemsci.org). This article is an open access article distributed under the terms and conditions of the Creative Commons Attribution license (http://creativecommons.org/licenses/by/4.0/). 